\title{
CT Angiography in Patients with Peripheral Arterial Disease
}

\section{Pramod Kumar Chhetri, ${ }^{1}$ Kripesh Thapa ${ }^{1}$}

${ }^{1}$ Department of Radiodiagnosis, College of Medical Sciences-Teaching Hospital, Bharatpur, Chitwan, Nepal.

\begin{abstract}
Background: Peripheral arterial disease is one of the most important causes of morbidity. Non-invasive characterization of peripheral arterial disease is possible by using CT angiography. The aim of this study is to evaluate CT angiographic findings in patients with peripheral arterial disease, to characterize lesion, risk factors and site of lesion.
\end{abstract}

\begin{abstract}
Methods: This hospital based prospective study was conducted in 40 consecutive patients with lower limb peripheral arterial disease who underwent CT angiography in the Department of Radiodiagnosis College of Medical Sciences-Teaching Hospital from January 2018 to Jan 2019.
\end{abstract}

\begin{abstract}
Results: Atherosclerotic peripheral disease was most common in elderly male patient with history of smoking, hypertension, diabetes or dyslipidemia and usually presents in the late stages with single or multiple arterial segmental involvement including the abdominal aorta. However, non- atherosclerosis peripheral arterial disease was seen in younger patients and presents with vascular thrombosis.
\end{abstract}

Conclusions: CT angiography is a reliable non-invasive imaging modality for evaluating patients with peripheral arterial disease and lesion characterization.

Keywords: CTA; Peripheral arterial disease.

\section{INTRODUCTION}

Peripheral arterial disease (PAD) refers to the disease process where blood flow to the extremities is impaired. Atherosclerotic stenosis or occlusion of the arteries is the most common etiology. ${ }^{1}$ Pathogenesis of atherosclerosis is complex and involves endothelial dysfunction, lipid disturbances, platelet activation, thrombosis, oxidative stress, vascular smooth muscle activation, altered matrix metabolism, remodeling and genetic factors. ${ }^{2}$ Risk factors for atherosclerosis are many and include mainly race, male gender, increasing age, smoking, diabetes mellitus, hypertension, dyslipidemia, homocystinemia, systemic inflammatory conditions and chronic renal insufficiency. ${ }^{1}$

Non-atherosclerotic peripheral arterial disease (NAPAD) is a heterogeneous group of conditions that presents with symptoms of leg ischemia but without atherosclerosis. ${ }^{3}$ Some of the causes include peripheral emboli, aneurysm thrombosis, arteritis, fibromuscular dysplasia, irradiation injury, coarctation of aorta, popliteal entrapment and primary vascular tumors. ${ }^{4}$ PAD affects about $12 \%$ of the general population though its incidence varies with age. ${ }^{5}$ For population below 70 years it ranges from $3-10 \%$ and for above 70 years ranges from $15-20 \% .{ }^{6,7} 60 \%$ of PAD patient are symptomatic and with approximately $10 \%$ presenting with intermittent claudication. Few patients have critical limb ischemia with persistent ischemic pain at rest, non- healing ulcer or gangrene. ${ }^{1,6} 1$ out of 100 patient with intermittent claudication will develop critical limb ischemia per year. ${ }^{8} 1-3 \%$ of patient will undergo amputation over a 5 year period. ${ }^{6}$ PAD is also associated with five fold increased risk of stroke and total mortality. ${ }^{9}$

The diagnosis of PAD is based on patient's history and physical examination. Though catheter based Digital Subtraction Angiography is the gold standard for diagnosis and evaluation of PAD, it is invasive and requires an interventionist. ${ }^{4}$ Ultrasound Doppler is a non- invasive and usually the first imaging modality for lesion characterization and flow abnormalities. ${ }^{6}$ However, the sensitivity varies widely from $46 \%$ to $88 \%$ for detecting stenosis. 10 With the introduction of multi row detectors, Computerized Tomography Angiography (CTA) is being increasingly used with advantages of shorter acquisition time, increased volume coverage, decreased contrast dose and improved spatial resolution. ${ }^{11,12}$ CTA has sensitivity of $96 \%$ and specificity of $95 \%$ in patients with PAD. ${ }^{13}$ Limitations of CTA are use of contrast agents, radiation exposure and overestimation of stenosis in severely calcified

Correspondence: Dr. Pramod Kumar Chhetri, Department of Radiodiagnosis, College of Medical Sciences, Bharatpur, Chitwan, Nepal. Email: dr.chhetripramod@gmail.com. Phone: +977-9845046687. Article received: 2020-04-30. Article accepted: 2020-06-19. 
Chhetri et al. CT Angiography in Patients with Peripheral Arterial Disease.

vessels. ${ }^{14}$ Due to the lack of any previous studies in Nepalese population presenting with lower limb PAD this study was thus undertaken to evaluate the CTA findings.

\section{METHODS}

40 consecutive patients with lower limb PAD after clinical or USG Doppler study who were referred for CTA in the Department of Radiodiagnosis, COMS-TH during one year period from Jan 2018 to Jan 2019 were included in this study. Patients with acute trauma, renal impairment, contrast allergy and those with previous history of PAD \& amputation were excluded. Detailed history was taken (in particular smoking, diabetes, hypertension, dyslipidemia) and patients were divided into groups according to their clinical presentation as proposed by Fontaine ${ }^{4}$ as shown below (Table 1).

\begin{tabular}{|ll|}
\hline Table 1. Fontaine's classification of PAD \\
\hline Clinical stage & Clinical presentation \\
I & Asymptomatic \\
II a & Intermittent claudication on walking $>$ \\
& 200 meters \\
II b & Intermittent claudication on walking $<$ \\
III & 200 meters \\
IV & Rest pain \\
\hline
\end{tabular}

Patients were advised NPO for 4-6 hours and written consent was taken prior to CTA (Toshiba 160 slice Aquilion Prime). About 100-150 ml of non- ionic water soluble contrast medium (Omnipaque $300 \mathrm{mg} /$ $\mathrm{dL}$ ) was injected into the antecubital vein at $4-5 \mathrm{ml} /$ second through an auto injector. Acquisition time for maximum enhancement was achieved by using automatic bolus tracking at region of interest (ROI) i.e., bifurcation of abdominal aorta. Trigger value was set at $180 \mathrm{HU}$. Scan was taken from the level of T12 till the foot. Image reconstructions were done using software like multiplanar reconstruction, maximum intensity projection and volume rendering technique.

Data were analyzed using Statistical Package for Social Sciences (SPSS) version 20. Results were analyzed using appropriate statistical methods. Statistical analysis was done with Chi-Square Test and compared with international standard literature.

\section{RESULTS}

40 consecutive patients with PAD underwent CTA during the study period. Of the 40 patients, $30(75 \%)$ patients were male and $10(25 \%)$ were female (male to female ratio of $3: 1$ ). The age of the patients ranged from 32 to 88 years (mean age $60.15 \pm 16.89$ years). The highest incidence of PAD was found in male patients above 70 years $(n=8)$ followed by male patients between $30-40$ years and $61-70$ years $(n=7$ each), but the statistics were not significant between
Table 2. Distribution of cases according to age and sex.

\begin{tabular}{|cccll|}
\hline $\begin{array}{c}\text { Age } \\
\text { group }\end{array}$ & Male (n) Female (n) & Total (n) & p-value \\
$30-40$ & 7 & 1 & $8(20)$ & \\
$41-50$ & 3 & 2 & $5(12.5)$ & \\
$51-60$ & 5 & 1 & $6(15)$ & $0.56^{*}$ \\
$61-70$ & 7 & 1 & $8(20)$ & \\
$>70$ & 8 & 5 & $13(32.5)$ & \\
Total & 30 & 10 & 40 & \\
\hline *Likelihood ratio test was applied when the minimal estimated \\
expected value was less than five.
\end{tabular}

male and female (p-value $=0.56$ ) $($ Table 2$)$. Smoking was the most common risk factor $(72.5 \%)$, followed by hypertension (65\%), diabetes $(50 \%)$ and dyslipidemia $(32.5 \%)$ in patient with atherosclerotic PAD (Table 3).

\begin{tabular}{|lcc|}
\hline $\begin{array}{l}\text { Table 3. Risk factor in patients with } \\
\text { PAD. }\end{array}$ & \\
\hline Risk factors & Frequency (n) & Percentage \\
Smoking & 29 & 72.5 \\
Hypertension & 26 & 65 \\
Diabetes & 20 & 50 \\
Dyslipidemia & 13 & 32.5 \\
\hline
\end{tabular}

Most of the patients ( $47.5 \%$ ) presented in stage IV Fontaine's clinical stage, followed by stage III $(32.5 \%)$, stage II b $(15 \%)$ and stage II a $(5 \%)$. Hence most of the patients presented late with gangrene (Table 4).

\begin{tabular}{|lll|}
\hline \multicolumn{2}{|c|}{ Table 4. Clinical presentation of patients with PAD. } \\
\hline Fontaine's stage & Frequency (n) & Percentage \\
II & 0 & 0 \\
II a & 2 & 5 \\
II b & 6 & 15 \\
III & 13 & 32.5 \\
IV & 19 & 47.5 \\
\hline
\end{tabular}

Among patients with PAD the commonest site of narrowing was the femoro- popliteal segment $(27.5 \%)$, followed by crural segment $(22.5 \%)$ and aorto-iliac segment (15\%). 15\% had narrowing of both the femoro-popliteal segment and aorto-iliac and $5 \%$ had narrowing of both the crural and aorto-iliac segments. In $15 \%$ all three segments were involved. Hence, single segment involvement was seen in $65 \%$, two segment involvement in 20 $\%$ and three segment involvement in $15 \%$ (Table 5).

Among the 40 patients with $\mathrm{PAD}$, atherosclerosis was the most common cause of stenosis in 27 patients $(67.5 \%)$ while the remaining 13 patients $(32.5 \%)$ had no evidence of atherosclerosis (Table 6). All the patients with non- atherosclerotic PAD had in-situ thrombus (Table 6). Atherosclerotic luminal narrowing was common in the elderly accounting for $48 \%$ in patients $>70$ 


\begin{tabular}{|c|c|c|}
\hline \multicolumn{3}{|c|}{$\begin{array}{l}\text { Table 5. Distribution of lesion according to segmental } \\
\text { involvement. }\end{array}$} \\
\hline Segments & Frequency (n) & Percentage \\
\hline Aorto-iliac & 6 & 15 \\
\hline Femoro-popliteal & 11 & 27.5 \\
\hline Crural & 9 & 22.5 \\
\hline $\begin{array}{l}\text { Aorto-iliac and Femoro- } \\
\text { popliteal }\end{array}$ & 6 & 15 \\
\hline Femoro-popliteal and crural & 2 & 5 \\
\hline Aorto-iliac and crural & 0 & 0 \\
\hline $\begin{array}{l}\text { All } 3 \text { segments (aorto- iliac, } \\
\text { femoro- popliteal and crural) }\end{array}$ & 6 & 15 \\
\hline
\end{tabular}

Table 6. Distribution according to type of PAD.

\begin{tabular}{|lll|}
\hline Type of PAD & Frequency (n) Percentage \\
Atherosclerotic & 27 & 67.5 \\
Non-atherosclerotic & 13 & 32.5 \\
\hline
\end{tabular}

years, $29.6 \%$ in $61-70$ years and $14.8 \%$ in $51-60$ years, while its prevalence in patients below 50 years was only $7.4 \%$. Thus atherosclerotic PAD was more significant in patients over 50 years. However, non- atherosclerosis PAD was seen in younger patients $(84.6 \%$ in patients below 50 years), accounting for $53.8 \%$ in patients between $30-40$ years and $30.8 \%$ in patients $41-50$ years and the difference was statistically significant ( $\mathrm{p}$-value $<0.001)$ (Table 7).

\begin{tabular}{|c|c|c|}
\hline \multicolumn{3}{|c|}{ Type of Pad } \\
\hline Atherosclerotic & Non-atherosclerotic & p-value \\
\hline $30-401(3.7)$ & $7(53.8)$ & \multirow{6}{*}{$0.001^{*}$} \\
\hline $41-501(3.7)$ & $4(30.8)$ & \\
\hline $51-604(14.8)$ & $2(15.4)$ & \\
\hline $61-708(29.6)$ & 0 & \\
\hline$>70 \quad 13(48.1)$ & 0 & \\
\hline Total 27(100) & $13(100)$ & \\
\hline
\end{tabular}

\section{DISCUSSION}

PAD is a public health burden and not only a major cause of morbidity but also increases cardiovascular related death by 2 to 6 folds. ${ }^{15}$ The main role of CTA is the detection and characterization of the lesion which aids in management. Of the 40 patients in this study, 30 $(75 \%)$ patients were male and $10(25 \%)$ were female (male to female ratio of 3:1). Similarly Kumar et al., ${ }^{16}$ and Algazaar et al., ${ }^{17}$ noted male predominance with male to female ratio of $6: 1$ and 1.5:1 respectively. However, Selvin ${ }^{7}$ and Meijer et al., ${ }^{18}$ found no gender differences in the prevalence of PAD.

Most (32.5\%) of the patients in this study were $>70$ years old followed by $20 \%$ between $60-70$ years. Similarly, Kumar et al. noted most of his patients $(44 \%)$ were in the $7^{\text {th }}$ decade. ${ }^{16}$ Interestingly, in this study $20 \%$ of cases were in the young age group of
30-40 years. These patients had non-atherosclerotic PAD with in situ thrombosis.

In this study, smoking was the most common risk factor $(72.5 \%)$ followed by hypertension $(65 \%)$, diabetes $(50 \%)$ and dyslipidemia (32.5\%). Dieter et al. found that tobacco smoking was closely linked with PAD and was three times more prevalent in smokers. ${ }^{19}$ Algazaar et al., similarly found smoking to be the most common risk factor $(56.67 \%)$ followed by hypertension (50\%) and diabetes $(10 \%) .{ }^{17}$ Cessation of smoking is associated with lower rates of amputation and longer survival in patients with PAD. ${ }^{20}$ Hence cessation of smoking need to be encouraged to reduce the morbidity and mortality associated with PAD.

Most of the patients (47.5\%) in our study presented late with gangrene (Fontaine's stage IV) followed by stage III $(32.5 \%)$ and stage II $(20 \%)$. In similar study by Kumar et al., in India most of the patients $(58 \%)$ presented late with gangrene (stage IV), $12 \%$ presented in stage III and $30 \%$ in stage II. ${ }^{16}$ However in a study by Creager et al., most patients presented with intermittent claudication (stage II). ${ }^{15}$ Similarly Algazaar et al., found intermittent claudication (stage II) to be the most common presentation $(40 \%)$ and gangrene (stage IV) to be the least common $(10 \%) .{ }^{17}$ The reason for the delayed presentation compared to western countries may be due to poor socio-economic background of the patients and non-availability of CTA in primary health centers. Most of the lesion in our study involved the femoro-popliteal segment $(27.5 \%)$, followed by crural segment $(22.5 \%)$ and aorto- iliac segment (15\%). Kumar et al also noted that most of the lesions involved the femoro-politeal segment $(47 \%)$ but followed by aorto-iliac segment (28\%). 16 However, Algazaar et al., found lesions affecting the crural artery in most of their patients $(62.5 \%)$ followed by femoropopliteal artery $(27.5 \%)$ and aorto- iliac artery $(10 \%){ }^{17}$

Twenty six patients $(65 \%)$ in this study had disease involving one segment, 8 patients $(20 \%)$ had involvement of 2 segments while 6 patients (15\%) had involvement of all 3 segments. Ozkan et al., examined segmental distribution of 626 symptomatic patients with PAD and found single segment involvement in $36 \%$ patients, 2 segments in $42 \%$ patients and all 3 segments involvement in $33.33 \%{ }^{21}$ In our study, patients with atherosclerotic disease had lesions involving more than one segment while most of the patients with non-atherosclerotic PAD had lesion in one segment only. In 4 patients $(10 \%)$ with PAD an incidental abdominal aortic aneurysm was found in this study. Barba et al., evaluated the abdominal aorta in 1166 patients with PAD and found prevalence of aortic 
aneurysm to be $13 \%{ }^{22}$ Hence, abdominal aorta needs to be evaluated as well in patients with PAD.

\section{CONCLUSIONS}

Atherosclerotic PAD was most common in elderly male patient with history of smoking, hypertension, diabetes or dyslipidemia and usually presents in the late stages with single or multiple arterial segmental involvement including the abdominal aorta.

\section{REFERENCES}

1. Schirmang TC, Ahn SH, Murphy TP, DubelGJ, Soares GM. Peripheral arterial disease: update of overview and treatment. Med Health R I. 2009 Dec;92(12):398-402.

2. Faxon DP, Fuster V, Libby $P$, et al. Atherosclerotic vascular disease conference: Writing Group III: pathophysiology. Circulation. 2004 Jun 1;109(21):2617-25.

3. Weinberg I, Jaff MR. Nonatherosclerotic arterial disorders of the lower extremities. Circulation. 2012 Jul 10;126(2):213-22.

4. Abdulhannan P, Russell DA, HomerVanniasinkam S.Peripheral arterial disease: a literature review. Br Med Bull. 2012 Dec 1;104 (1):21-39.

5. Criqui $\mathrm{MH}$, Fronek $\mathrm{A}$, Barrett-Connor $\mathrm{E}$, Klauber MR, Gabriel S, Goodman D. The prevalence of peripheral arterial disease in a defined population. Circulation. 1985 Mar;71 (3):510-5.

6. Norgren L, Hiatt WR, Dormandy JA, et al. Inter -Society Consensus for the Management of Peripheral Arterial Disease (TASC II). J Vasc Surg. 2007 Jan;45 Suppl S:S5-67.

7. Selvin E. Prevalence of and Risk Factors for Peripheral Arterial Disease in the United States: Results from the national health and nutrition examination Survey, 1999-2000. Circulation. 2004 Jul 26;110(6):738-43.

8. Ubbink DT. Toe blood pressure measurements in patients suspected of leg ischaemia: a new laser Doppler device compared with photoplethysmography. Eur J VascEndovasc Surg Off J Eur Soc Vasc Surg. 2004 Jun;27 (6):629-34.

9. Steg PG, Bhatt DL, Wilson PWF, et al. Oneyear cardiovascular event rates in outpatients with atherothrombosis. JAMA. 2007 Mar 21;297(11):1197-206.

10. Krnic A, Vucic N, Sucic Z. Duplex scanning compared with intra-arterial angiography in diagnosing peripheral arterial disease: three analytical approaches. VASA Z Gefasskrankheiten. 2006 May;35(2):86-91.

11. Artazcoz AV. Diagnosis of Peripheral Vascular Disease: Current Perspectives. J Anesth Clin Res. 2015 Feb 20;6(2):1-7.

12. Rubin GD, Shiau MC, Leung AN, Kee ST, Logan LJ, Sofilos MC. Aorta and iliac
However, non-atherosclerosis PAD was seen in younger patients and presents with vascular thrombosis.

\section{Limitations of the study}

The most important limitation of our study was the small sample size. The distinction between acute and chronic disease, the degree of stenosis and the status of collateral vessels were also not evaluated in this study. arteries: single versus multiple detector-row helical CT angiography. Radiology. 2000 Jun;215(3):670-6.

13. Rubin GD, Dake MD, Napel S, et al. Spiral CT of renal artery stenosis: comparison of three-dimensional rendering techniques. Radiology. 1994 Jan;190(1):181-9.

14. Jens S, KoelemayMJW, Reekers JA, Bipat S. Diagnostic performance of computed tomography angiography and contrast-enhanced magnetic resonance angiography in patients with critical limb ischaemia and intermittent claudication: systematic review and metaanalysis. Eur Radiol. 2013 Nov;23(11):310414.

15. Creager MA, Loscalzo J. Vascular Diseases of the Extremities. In: Fauci A, Longo D, editors. Harrison's Principles of Internal Medicine. Volume 2. 17th ed. USA: McGraw-Hill Companies. 2008;1568-9.

16. Kumar UK, Grover SB, Jain SK, Bansal S, Prasad J, Thukral BB. Evaluation of peripheral arterial occlusive disease by computed tomography angiography. Int J Res Med Sci. 2016 Dec 19;4(11):4675-82.

17. Algazzar MAA, ElzawawiMSE, AlhawaryKES, Mousa WA. Role of Multi-Detector Computed Tomography Angiography in the Evaluation of Lower Limb Ischemia. International Journal of Medical Imaging. 2014 Sep 30;2(5):125.

18. Meijer WT, Hoes AW, Rutgers D, Bots ML, Hofman A, Grobbee DE. Peripheral arterial disease in the elderly: The Rotterdam Study. ArteriosclerThrombVasc Biol. 1998 Feb;18 (2):185-92.

19. Dieter RS, Chu WW, Pacanowski JP, Mc Bride PE, TankeTE. The significanceof lower extremity peripheral arterial disease. ClinCardiol. 2002;25:3-10.

20. Jonason T, Bergström R. Cessation of smoking in patients with intermittent claudication. Effects on the risk of peripheral vascular complications, myocardial infarction and mortality. Acta Med Scand. 1987;221(3):25360.

21. Ozkan U, Oguzkurt L, Tercan F. Atherosclerotic risk factors and segmental distribution in symptomatic peripheral artery disease. J VascIntervRadiol. 2009 Apr;20 
Chhetri et al. CT Angiography in Patients with Peripheral Arterial Disease.

(4):437-41. aortic aneurysm in patients with peripheral

22. Barba A, Estallo L, Rodríguez L, Baquer M, artery disease. Eur J VascEndovasc Surg. 2005 Vega de Céniga M. Detection of abdominal Nov;30(5):504-8.

Citation: Chhetri PK, Thapa K. CT Angiography in Patients with Peripheral Arterial Disease. JCMS Nepal. 2020; 16(2):78-82. 